\title{
Information and Communication Technology in Organizational Operations. Ethical and Operational Implications
}

http://doi.org/10.21272/bel.4(4).6-13.2020

\section{Andreas Karaoulanis}

PhD, MBA, MScENG, MSc, BEng, Business consultant, Thessaloniki, Greece; Honorary Professor of Business Management for PhD candidates at IMSR center, India

\section{Alexandros-Christos Karaoulanis}

High School student, Thessaloniki, Greece

\begin{abstract}
In this paper, we discuss Information and Communication technology in terms of knowledge dissemination, not only inside the organization but also how it interacts with the surroundings via such systems. The open systems theory and the stakeholder theory as integral parts of the organization's operations are briefly examined as their importance is a factor that needs to be taken under consideration in terms of applying Information and Communication Technology. Leadership and how it is exercised throughout the implementation and operation of such systems is another paragon that is discussed, while ethical considerations might arise from the misuse of them. Finally, another significant paragon for the organizational sustainability, the value creation for both the customers and the organization is discussed under the prism of the Information and Communication Systems used in the company in question. The implications of this paper are important as it can be seen as the springboard towards bigger research on the topic of Information and Communication Systems and their societal and organizational implication. Another part that needs to be examined is the leadership approach of the whole process as there are ethical considerations that increase day by day, especially in large corporations. These considerations need to be addressed clearly and in-depth and need to abide by the stakeholder theory to create better societies in the future.
\end{abstract}

Keywords: ICT, Leadership, Knowledge, Operations, Open Systems Theory, Stakeholder Theory, Ethics, Society.

JEL Classification:.C44, D8.

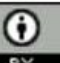

This work is licensed under a Creative Commons Attribution 4.0 International License

Cite as: Karaoulanis, A., Karaoulanis, A.-C. (2020). Information and Communication Technology in Organizational Operations. Ethical and Operational Implications. Business Ethics and Leadership, 4(4), 6-13. http://doi.org/10.21272/bel.4(4).6-13.2020.

(C) The Authors, 2020. This article is published with open access at Sumy State University.

\section{Introduction}

The world around us is changing rapidly. This new world needs a new way of thinking - a new approach. As organizations are vivid parts of this world, they need to adapt to this mentality. Under this prism, we need to consider that entrepreneurial leadership, which in a high degree defines the organizational operations, needs to work towards the innovation creation, which will lead to growth (Uhl-Bien et al., 2017). This approach has led organizations to adapt to new systems, which enabled them to manage things and employees more innovatively and effectively. In this paper, we will examine five key questions regarding the organizational way of operating. These questions are the following:

1. How are people in organizations lead, managed and coordinated?

2. How do people collaborate within an organization and in-between organizations?

3. How do people inform themselves in an organization?

4. How are ICT ${ }^{1}$ used in these (above described) processes?

5. What types of ICT are used?

By answering the above questions, we will be able to have a more spherical view of how new organizations operate via the use of ICT and how this kind of operation yields a positive result in terms of people

${ }^{1}$ ICT: Information and Communication Technology 
management, information communication and dissemination inside the organizational boundaries and what kind of ICTs are in use to deliver the appropriate consequence.

ICT systems as means of management. According to Aghaee (2018), information is a vital part of human communication. This fact per se makes information a powerful tool in terms of KM (Knowledge Management) and DM (Decision Making) (Aghaee, 2018). Data can be assertive, declarative, expressive, directive (Aghaee, 2018). In terms of how organizations operate, information can lead to decision and decision to action (Aghaee, 2018), as shown in the following Figure 1.

\section{INFORMATION

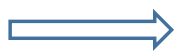 \\ DECISION

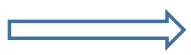

ACTION

Figure 1. The Correlation between Information, Decision and Action

Source: Compiled by the author

As management is a core procedure in all businesses, thus in all organizations and as it is all about decision making based on useful information (Aghaee, 2018), we can understand that management needs to be based on useful information. By "good," we mean reliable and good quality information because it is evident that the right quality information can lead to more accurate decision-making. Management in organizations, as a core operation, is based on how this information is communicated from managers to subordinates in terms of how the latest are managed and how accurate this information is in terms of the decision-making process.

People in organizations are lead, managed, and coordinated via ICT systems that are functioning to convey information between the organization members, help that information reach the decision-makers (managers), and help them make the appropriate decision. Such a decision will lead their subordinates into action. The whole process needs coordination between the different parts of this organizational "equation" comprised of both employees and their managers. Such coordination is achieved via the proper use of the ICT systems, which can deliver information, decisions and schedule their execution. According to Iqbal (2018a), the communication software embedded into ICT systems enables the communication between different computing devices into the organizational network. In that way, both communication and coordination occur. According to Mithas et al. (2011), senior leaders should implement the right IT $^{2}$ infrastructure and information management capability to boost the whole company's performance. It underlines the importance of ICT systems in terms of management and performance in an organizational context.

Collaboration as key element within and between organizations. As we saw in the previous chapter, management uses information and information systems to lead, manage and coordinate people who work in organizations. But how these very people tend to collaborate within the organization and in-between organizations? It is evident that as globalization increases and competition grows, firms are becoming increasingly dependent upon group work and collaboration between their members (Pervan et al., 2004). As we saw above, communication software embedded inside the organization's ICT systems connects the different computing devices inside the organizational network (Iqbal, 2018a). In that way, people can collaborate inside the organization.

Such systems differ from one organization to another. There is simple software like slack in small organizations that enables personnel to exchange info, files, and even voice calls between the different departments. In larger organizations where there is a distance between the several organizational premises, software like skype or other video conferencing software like Adobe connects, Blue Jeans, Zoom, etc. are used to help employees or even managers exchange knowledge, files, etc., in real-time. Other software towards that direction is $\mathrm{CRM}^{3}$ or ERP $^{4}$ software, which helps collaboration and knowledge exchange. Also, big organizations usually operate based on an intranet system (i.e., banks), which runs in real-time and allows the communication between employees (Iqbal, 2018). Such systems can be seen as particular types of ICT systems (Iqbal, 2018a). Other kinds of ICT systems like extranet are used to facilitate communication between external stakeholders like suppliers and partners and the core organization (Iqbal, 2018a).

Also, employees can have access to cloud computing software, which enables their collaboration. Software like Google Drive enables employees to work together in the cloud simultaneously and even to interact on the same paper simultaneously. When employees need to collaborate in- between organizations, proximity dimensions that are involved like geographical, cognitive, organizational, and social proximity, are important paragons in what we call inter-organizational collaboration (Steinmo et al., 2016). A quite new and impressive

\footnotetext{
${ }^{2}$ IT: Information Technology

${ }^{3}$ C.R.M: Customer Relations Management systems

${ }^{4}$ E.R.P.: Enterprise Resource Planning systems
} 
paradigm of collaboration between employees on an in- between organizations dimension is the KPMG platform which is called the Hub. This platform is a kind of internal social collaboration platform implemented across KPMG's international network and has now been adopted by many users across multiple KPMG's member firms. In that way, professionals can connect, communicate, collaborate, and become even more creative (Hughes et al., 2013). As organizations are value creation systems (Iqbal, 2018b), they try to create value and under this prism, they collaborate with other organizations via channels like E-commerce and/or Ebusiness (Iqbal, 2018b). Of course, such systems involve the use of ICT. For example, the E-business model uses ICT in the supply chain (Iqbal, 2018b), etc.

Another way of collaborating between organizations is the P2P e-Commerce systems that comprise ICT systems to support the partnership chain, a network of organizations collaborating to deliver value to their customers (Iqbal, 2018b). As we can see, there are several ways of communicating between organizations and between organizations and stakeholders ${ }^{6}$. Such systems are essential. This communication and information exchange is vital and a paragon that can be proved very important in the organization's sustainability, especially if it will be examined under the open system's prism and the stakeholder theories. Although in the past, organizations were considered closed systems that did not influence their surrounding environment, this approach changed over the years and gave us the birth of the "open systems" theory, which is a holistic approach to how the whole system operates.

According to the open systems theory, there is an interconnection between organizations and the societies they operate, as they can be seen as an integral part of it. An exciting definition of the open system theory is the following: "The open system theory is seeing an organization as an open and networked structure that is part of and affected by external environment" (Jung \& Vakharia, 2019).

The surrounding environment influences organizations in mainly two ways: specifically, and generally.

$>$ Specifically, via the: network of suppliers, distributors, government agencies, competitors

$>$ Generally, via the: cultural values, economic conditions, legal/political environment, quality of education (Referenceforbusiness,com, n.d.).

The open system theory also assumes that this interaction and influence can be quite different in terms of large organizations. Large organizations are comprised of many subsystems, each of which receives inputs from other adjacent subsystems. These inputs are then turned into outputs and can be used by other subsystems. These subsystems can be departments but also patterns of activity. (Referenceforbusiness, com, n.d.). According to the open systems theory, there is a subsystems hierarchy. In other words, not all subsystems are equally essential, which means that the failure of a specific subsystem will not necessarily affect a fundamental and/or crucial way for the rest of them. It comes in juxtaposition with the traditional mechanistic theories, which underline that a malfunction in any part of an organizational operating system would have an equally significant impact on the rest of it as a whole (Referenceforbusiness, com, n.d.). We can assume from the above that the open system theory is quite agile and decentralized. Another critical theory that plays a vital role in how organizations operate, their social responsibility and their interaction via the use of ICT systems is the stakeholder theory.

The stakeholder theory is a widely understood and used concept in nowadays business world. The theory states that the purpose of a business is to create value for both stakeholders and shareholders. Any business needs to consider customers, suppliers, employees, communities, and shareholders (Stakeholdermap.com, n.d.). What is essential to understand is that there is an interconnection between the open system theory and the stakeholder one. Organizations, as available systems, interact with their surroundings (stakeholders), and this interaction is significant as it creates a two ways path via which organizations add value to their stakeholders and this value returns to the organizations by adding value to their shareholders. It also has to do with the organization's corporate social responsibility and the company's culture and how it is depicted in terms of the company's relation to its stakeholders.

In the following figure we can see a depiction of some of the most important stakeholders and their interaction with the organizations inside the context of a society:

\footnotetext{
${ }^{5} \mathrm{KPMG}$ is a global network of independent member firms offering audit, tax and advisory services (KPMG, n.d.)

${ }^{6}$ Stakeholders: "A stakeholder is anyone who has an interest in a project, business or organization" (Blackburn, 2019)
} 


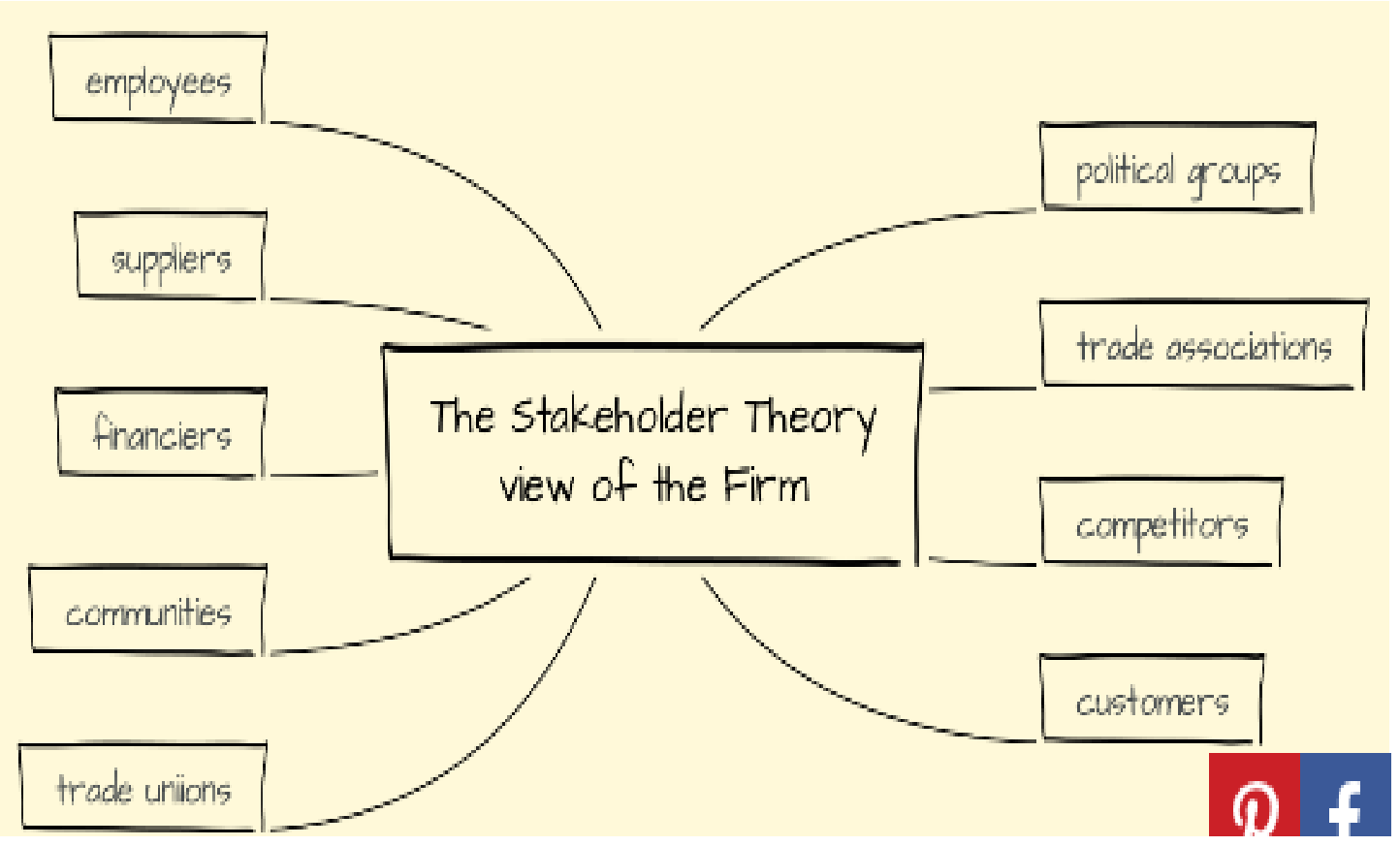

Figure 2. Some of the Stakeholders who Interact with the Company

Source: Stakeholdermap.com, n.d.

Significant companies worldwide have understood the importance of the stakeholder theory, which imposes an ethical commitment for companies that need to pursue profit for their shareholders and add value to their stakeholders and society/environment as a whole. Nowadays, humanity faces many environmental catastrophic consequences that spring from the human's irrational way of seeing business. Both the theories that we briefly examined in the above paragraphs, the stakeholder and the open systems one, are two essential theories that are based on communication between organizations, between organizations and their stakeholders, and of course, between organizations and the societies in which they operate. ICT systems are an essential paragon in all of them and can be seen as the bridge that connects these paragons of the corporate world. Collaboration is a necessary element in organizations, and it covers the whole spectrum of employees from top managerial positions to simple employees like the drivers, etc. As we saw until now, ICT systems help towards information dissemination in an organizational context.

According to Beynon-Davies (2009: 76), signs are vital in business organizations. Employees need to use them to be informed. While they use symbols to get the required information, they face the three dimensions of signs: forma, informa and performa. In that way, signs link the physical or technical world with the social through the psychological one (Beynon-Davies, 2009: 77). Therefore, the information dissemination to employees via signs is an essential element and supports decision making about appropriate actions in particular circumstances (Beynon-Davies, 2018: 83). Another way of getting informed is by the so-called access channels (telecommunications) (Iqbal, 2018c.). During this process, they use several devices like telephony, personal computers, RFID ${ }^{7}$ tags, mobile devices etc. (Iqbal, 2018c.). They also use LAN $^{8}$, WAN, VAN systems which are different types of networks which get in contact communication nodes which are closely or remotely. Other ways that employees use to be informed are WiFi, WiMax, software like skype, or other videoconference software like Adobe Connect, Blue Jeans, and the internet.

ICT systems infrastructure and its role as value creation tools in organizations. As we can see from the above, information is an essential component of an organization's eurythmic function and ICT systems are playing a vital role in disseminating information via the company's communication infrastructure. According to Iqbal (2018c), the communication infrastructure that a company uses in terms of its ICT can be described as follows:

\footnotetext{
${ }^{7}$ R.F.ID: Radio Frequency Identification

${ }^{8}$ LAN: A type of communication network in which the nodes are located relatively close. Stands for Local Area Network WAN: A type of communication network in which the nodes are geographically remote. Stands for Wide Area Network VAN: A network which third party organization sets up and maintains selling rights to use it (Iqbal, 2018c).
} 
1. Access channels and stakeholders where ICT systems utilize a subset of telecommunications which are known as data communications. These channels are:

$>$ The access devices which enable access to organization's ICT,

$>$ Telephony which of course includes mobile and fixed phones, fax, telex, touch tone service, call centers etc.,

Television (i.e., pay per view services),

Personal computers,

Multimedia kiosks and public internet access points,

Mobile devices such tablets, PDAs and WAP enabled mobile phones,

RFID tags which are access devices that can be incorporated into products, animals or persons,

Multichannel access centers which integrate various access channels into the organization, communication networks (LAN, VAN, WAN etc.) and of course

$>$ Internet

2. Front - end ICT.

3. Delivery of intangible goods and services.

4. Back- End ICT.

5. Front-End, Back-End ICT integration.

6. Securing data (Iqbal, 2018c).

In Figure 3 below we can see the technical communication infrastructure of an organization as briefly was described in the above paragraph (Iqbal, 2018c).

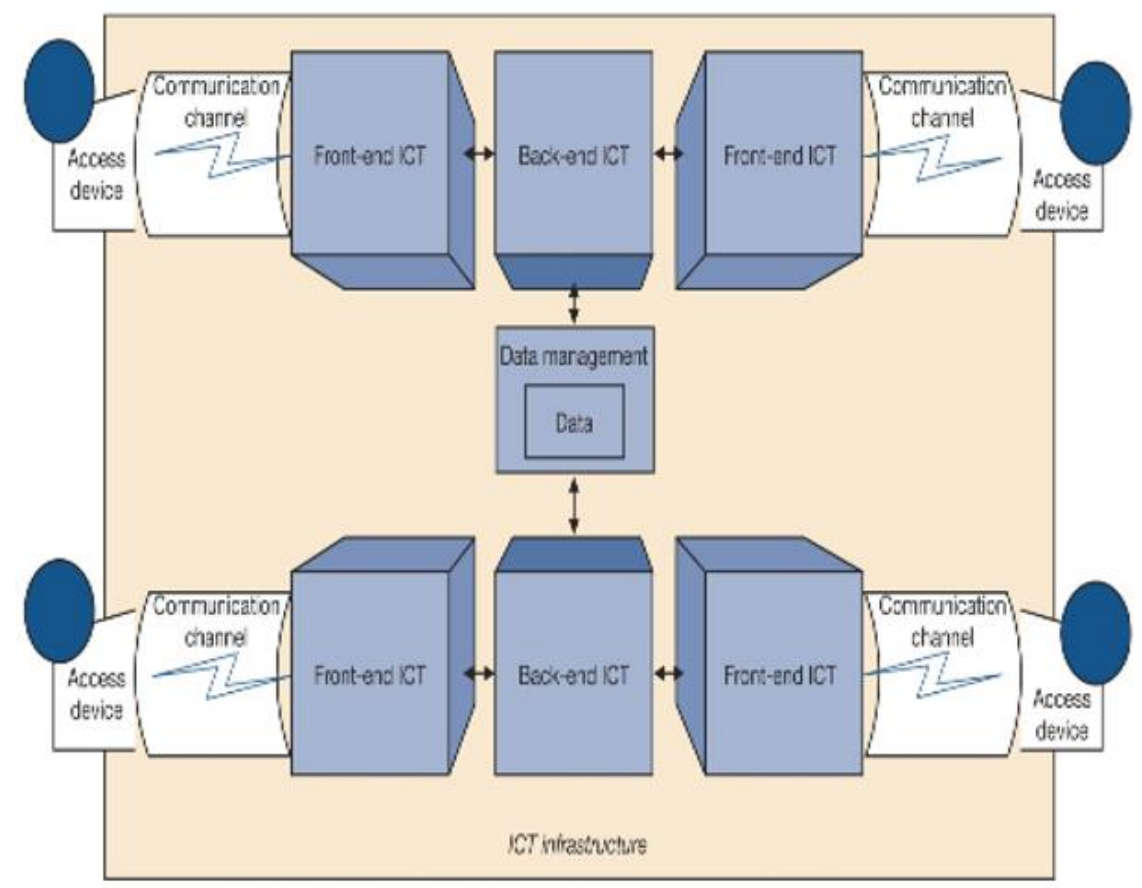

Figure 3. Technical Communication Infrastructure

Source: Iqbal, 2018c

But the usage of ICT systems in managing, leading, and coordinating people within an organization, in information dissemination among them, in collaboration between them and with other organizations, is set up to create value (Beynon-Davies, 2009). Porter and Millar (1985, cited in Beynon-Davies, 2009) describe importance as the key output of a business organization. It is essential if we can understand that this value creation from organizations is vital to its environment. This interaction is vividly depicted in Figure 4 (BeynonDavies, 2009: 246). 


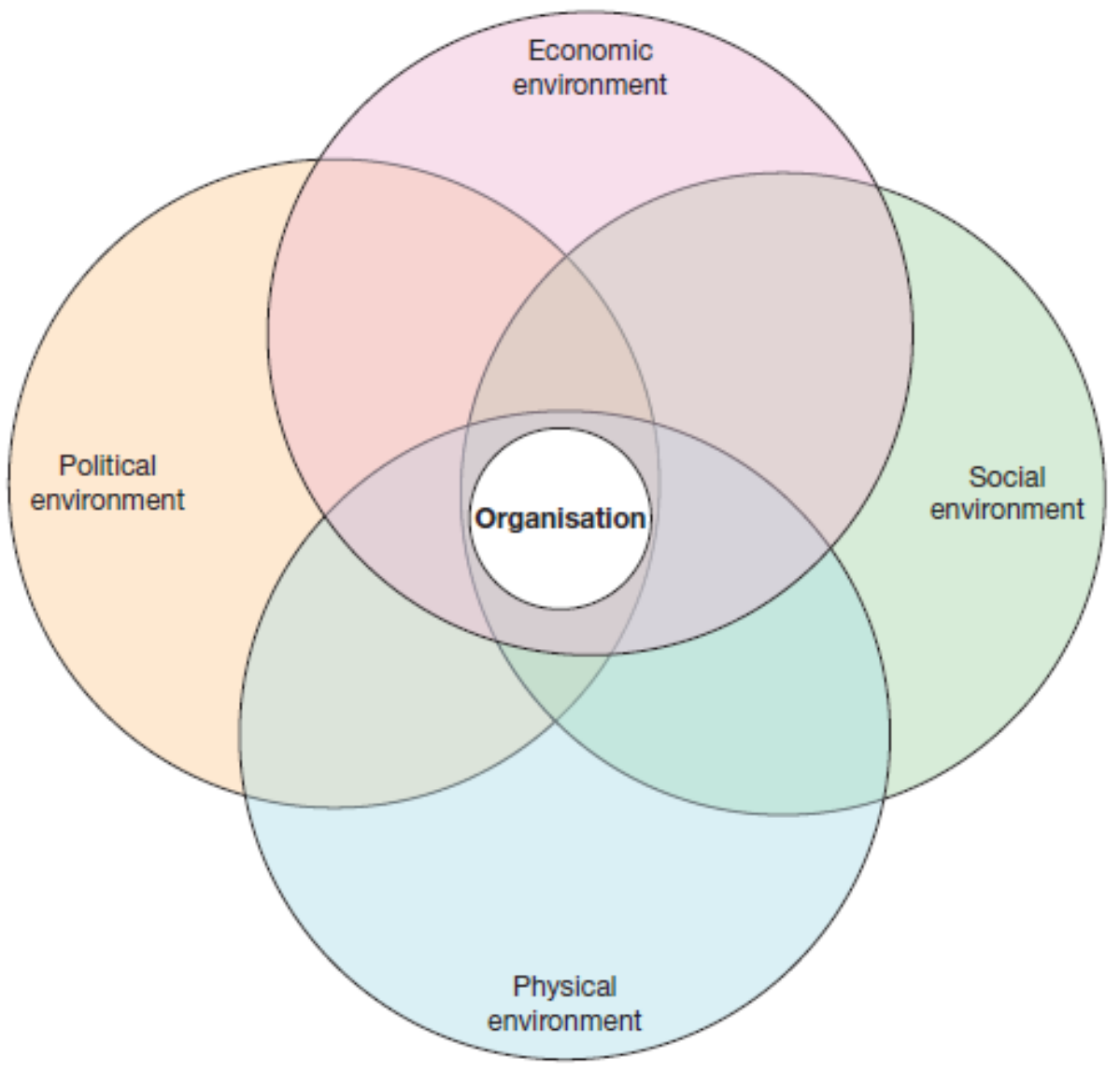

Figure 4. The Environments with which Organizations Interact

Source: Beynon-Davies, 2009, p.246

In Figure 4, we can see why the open systems theory is vital for any organization and why CEOs need to understand its importance. We can see that organizations are in communication and ideas and information exchange with many subsystems inside the society they operate. Such subsystems are the economic environment which can be manipulated and influenced by both the organization and the markets/society inside which the organization operates. It also is the social environment which is partially depicted through the stakeholder theory and of course the physical environment which is very important due to the consequences that the whole planet might face in case it will not be protected. Another subsystem is the political environment which can or cannot create stability for the organization's smooth operation, as it can influence positively or negatively both the markets in which the organization operates and the societies.

All these interactions that we just described can be realized via the use of the ICT systems that we discussed until now and this is another fundamental reason why their presence is vital for each organization's operations. As organizations are in continuous information exchange with it, as seen in Figure 4, as we discussed, ICT systems play a paramount role in that direction. Under this prism, we need to see the usage of ICT systems within an organization described in the previous chapters as value creation systems. So, ICT systems are used to create value to organizations and the value exchange that they evangelize is coming in mainly two forms, goods and services (Beynon-Davies, 2009: 246). Value creation is the cornerstone upon which sustainable development can be based, especially when it targets customers as the organization's sustainability springs from the value that can be created for the company's customers, as such value will increase customer retention brand name thus R.O.I. ${ }^{9}$ on the long run.

According to a research that was contacted by $\mathrm{Xu}$ et al. (2014), service leadership and customizationpersonalization control as essential elements of the operations management process can play a vital role for the ICT service providers' brand equity, or in simpler words, for the brand name that can be created for them as the result of the value that they add to their customers. The important aspect is understanding that the right use of IC technology via the prism of the exercise of the right leadership style can add value to customers and increase their retention, thus R.O.I for the company in question as we saw in previous chapters. It is also a paragon that can have a significant positive impact in the company's operations management processes and 
techniques. From all the above, we can easily understand that ICT systems are used mainly towards a value creation direction according to the organizations' identity/ structure/ form. Under this notion, ICT systems can be used to help people manage information flow, e-commerce (B2B, B2C, P2P, C2C), procurement and supply chain (Iqbal, 2018c).

According to (Tyworth, 2014), an organization's identity shapes how ICT systems are used, thus shapes their entire infrastructure. As there is such kind of interaction, Tyworth (2014) stress that organizational identity can act both as a catalyst or as a constraint on its ICT system development and as relatively static and not easy to change, it can create serious impediments to large- scale integrations of different organizational systems, therefore ICT systems too (Tyworth, 2014). Another parameter that is very important for all organizations is training. Training has to do with adding value to all organizations' most asset: their people as organizations need to have a high retention rate regarding their most valuable, at least, employees. ICT systems can play a vital role in that direction, as they can contribute useful tools that can create better educational conditions for business, while companies need to develop effective methods that can combine ICT with crucial learning factors (Genlott and Gronlund, 2016).

ICT systems are essential for every organization. They have to do with knowledge dissemination and communication of that knowledge between people inside the organization and not only. As knowledge can be seen as a power that professionals hold in their hands, this knowledge must be transmitted between professionals that work in the same space. So, another important aspect that needs to be examined in the future regarding the use of ICT systems is the appropriateness of the usage of ICT systems between professionals and how this knowledge is disseminated properly (Butler, 2016). In other words, there should be an ethical dimension in terms of the use of the ICT systems, not only between the stakeholders/professionals but also between stakeholders who interact, as we saw in figure 4 between the organization and the surrounding environments. It is essential here to notice that how we use ICT has to do with what future we expect to have in the years to come. The ethical considerations that we underlined above are very important and what we always need to have in mind is that ICT can be used for the good and for the bad. The way leadership approaches the whole issue is critical and can positively or negatively impact society. The use of ICT must be aligned with the stakeholder theory so that humans and the communities will be in the epicenter of business and that knowledge and information will be disseminated and communicated via the use of ICT properly and constructively.

\section{Conclusions}

ICT systems are essential components of the organizational processes. They can be the levers towards value creation, and thus, they contribute to that direction via people management, information flow, the organization's interaction within its system, and its environment at multiple levels (supply chain, e-commerce, etc). The several forms of ICT systems described in this paper can be integrated inside the internal organizational context and shaped according to the corporate identity. This identity focuses on the organization's primary objectives and therefore manipulates how ICT systems will be implemented and evolve inside the organization. Such evolution is significant but challenging too in parallel, as it has to do with the difficult procedure of changing them towards that evolution. ICT systems also need to be seen based on knowledge dissemination as embedded paragons of the open systems theory and the stakeholder theory. As such, we need to understand that there is also an ethical dimension regarding how they are used and that their right and professional use has to do with the leadership and how it is exercised inside the company in question.

Author Contributions. Conceptualization, Alexandros-Christos Karaoulanis; data curation, AlexandrosChristos Karaoulanis; formal analysis, Alexandros-Christos Karaoulanis; investigation, Alexandros-Christos Karaoulanis, Andreas Karaoulanis; methodology, Andreas Karaoulanis; project administration, Andreas Karaoulanis; resources, Alexandros-Christos Karaoulanis, Andreas Karaoulanis; software, AlexandrosChristos Karaoulanis; supervision, Andreas Karaoulanis; validation, Alexandros-Christos Karaoulanis, Andreas Karaoulanis; visualization, Alexandros-Christos Karaoulanis; writing - original draft, AlexandrosChristos Karaoulanis, Andreas Karaoulanis; writing - review \& editing, Alexandros-Christos Karaoulanis, Andreas Karaoulanis.

Funding. There is no funding for this research.

\section{References}

1. Aghaee, N. (2018). Lecture 3, IS/IT for Organizing, Communicating, and Coordinating I, Linnaeus University Department of Informatics, Unpublished. 
2. Blackburn, M. (2019). What is stakeholder theory? Projectmanager.com [blog]. Available at: https://www.projectmanager.com/blog/what-is-stakeholder-theory. Accessed 06 October 2019.

3. Beynon-Davies, P. (2009). The 'language' of informatics: The nature of information systems. International Journal of Information Management, 29(2), 92-103. DOI:10.1016/j.ijinfomgt.2008.11.002.

4. Butler, C. (2016). Being appropriately professional: the interaction between professionalism, ICT and knowledge transfer. New Technology, Work and Employment, 31(2), 132-145. https://doi.org/10.1111/ntwe.12064.

5. Genlott, A.A. \& Grönlund, A. (2016). Closing the gaps - Improving literacy and mathematics by ictenchanced collaboration. Computers and Education, 99, 68-80. Available at: file:///C:/Users/lushi/Downloads/closing-the-gaps-improving-literacy-and-mathematics-by-ict-enhancedcollaboration.pdf.

6. Hughes, C. \& Chapel, A. (2013). Connect, communicate, collaborate and create: Implementing an enterprise-wide social collaboration platform at KPMG - Part two: Realizing value. Business Information Review, 30(4), 191-195. https://doi.org/10.1177/0266382113507378.

7. Iqbal, S. (2018a). Lecture 5, IS/IT for Organizing, Communicating, and Coordinating I, Linnaeus University Department of Informatics, Unpublished.

8. Iqbal, S. (2018b). Lecture 6, IS/IT for Organizing, Communicating, and Coordinating I, Linnaeus University Department of Informatics, Unpublished.

9. Iqbal, S. (2018c). Lecture 4, IS/IT for Organizing, Communicating, and Coordinating I, Linnaeus University Department of Informatics, Unpublished.

10.Jung, Y. \& Vakharia, N. (2019). Open Systems Theory for Arts and Cultural Organizations: Linking Structure and Performance. The Journal of Arts Management, Law, and Society, 49(4), 257-273. DOI:10.1080/10632921.2019.1617813.

11.KPMG, n.d. About us [online]. Available at: https://home.kpmg.com/xx/en/home/about.html. Accessed 13 October 2018.

12.Mithas, S., Ramasubbu, N. \& Sambamurthy, V. (2011). How Information Management Capability Influences Firm Performance. MIS Quarterly, 35(1), 237-256. DOI:10.2307/23043496.

13.Pervan, G., Lewis, L.F. \& Bajwa, D.S. (2004). Adoption and Use of Electronic Meeting Systems in Large Australian and New Zealand Organizations. Group Decision and Negotiation, 13(5), 403-414. Available at: https://link.springer.com/article/10.1023/B:GRUP.0000045749.26839.4d.

14.Referenceforbusiness.com, n.d. Organization Theory [online]. Available at: https://www.referenceforbusiness.com/small/Op-Qu/Organization-Theory.html. Accessed 06 October 2019.

15.Stakeholdermap.com, n.d. Stakeholder analysis, project management, templates and advice. [online]. Available at: https://www.stakeholdermap.com/stakeholder-theory.html. Accessed 06 October 2019.

16.Steinmo, M. \& Rasmussen, E. (2016). How firms collaborate with public research organizations: The evolution of proximity dimensions in successful innovation projects. Journal of Business Research, 69(3), 1250-1259. DOI:10.1016/j.jbusres.2015.09.006.

17.Tyworth, M. (2014). Organizational identity and information systems: how organizational ICT reflect who an organization is. European Journal of Information Systems, 23(1), 69-83. https://doi.org/10.1057/ejis.2013.32.

18.Uhl-Bien, M. \& Arena, M. (2017). Complexity leadership: Enabling people and organizations for adaptability. Organizational Dynamics, 46(1), 9-20. Available at: https://coek.info/pdf-complexityleadership-.html.

19.Xu, X., Thong, J.Y.L. \& Venkatesh, V. (2014). Effects of ICT Service Innovation and Complementary Strategies on Brand Equity and Customer Loyalty in a Consumer Technology Market. Information systems research, 25(4), 710-729. Available https://pdfs.semanticscholar.org/fce4/42e8d73ea2f667abc652a827323777e7b92e.pdf. 